Short Communication

\title{
Preparation of Porous Carbon-Manganese Dioxide Nanocomposite as a Supercapacitor Electrode
}

\author{
Yang Ren ${ }^{1, *}$, Chenggong Sun ${ }^{2}$, Mingjun Song ${ }^{1}$, Lintong Wang ${ }^{1}$ \\ ${ }^{1}$ College of Chemistry \& Chemical and Environmental Engineering, Weifang University, No. 5147 \\ Dongfeng St, Weifang, Shandong, 261061, P.R. China \\ ${ }^{2}$ Shandong Industrial Ceramics Research \& Design Institute Co., Ltd., No. 128, Yumin Rd, Zibo, \\ Shandong, 255000, P.R. China \\ *E-mail: renyangwf@163.com
}

doi: $10.20964 / 2016.12 .42$

Received: 5 September 2016 / Accepted: 4 October 2016 / Published: 10 November 2016

Activated porous carbons were prepared from paulownia flower by carbonization and subsequent alkali activation. Then $\mathrm{MnO}_{2}-\mathrm{AC}_{3}$ composite was synthesized by the electrochemical deposition of manganese oxide nanostructures on the surface of as-prepared activated porous carbons. The $\mathrm{MnO}_{2}-$ $\mathrm{AC}_{3}$ electrode demonstrates outstanding capacitive behavior with low charge transfer resistance owing to the double layer charge storage and unique pore structure (coexistence of micropores, mesopores and macropores) of activated porous carbons. The stability of $\mathrm{MnO}_{2}-\mathrm{AC}_{3}$ electrode was affirmed by 1000 successive charge/discharge cycles. The remarkable capacitive behavior and excellent stability make $\mathrm{MnO}_{2}-\mathrm{AC}_{3}$ promising material with potential application in supercapacitor.

Keywords: Supercapacitor; Activated porous carbon; Manganese oxide; Electrodeposition; Cycle life

\section{FULL TEXT}

(C) 2016 The Authors. Published by ESG (www.electrochemsci.org). This article is an open access article distributed under the terms and conditions of the Creative Commons Attribution license (http://creativecommons.org/licenses/by/4.0/). 